\title{
The Psychological Impact of Infertility in the Male Able Bodied and Spinal Cord Injured Population
}

\author{
Mansoureh Karimzadeh • Nasser Salsabili • \\ Firouzeh Akbariasbagh · Abdoulrassol Mehrsai
}

Published online: 14 November 2006

(C) Springer Science+Business Media, LLC 2006

\begin{abstract}
Background Parenthood is one of the major transitions in adult life for both men and women, which is associated with major emotional sequels. This study was performed to determine the psychological impact of infertility in healthy infertile (HI) male and their partners compared to spinal cord injured (SCI) male patients and their partners.

Methods In this descriptive analytical study 115 subjects who attended for IVF/ ICSI program recruited. Thirty-one HI male but twenty of their partners, and 34 SCI male but thirty of their partners agreed to complete the symptoms checklist (SCL90) and cattle anxiety questionnaires. The Farsi version of these questionnaires were used to evaluate psychological problems such as anxiety, depression, hypochondriasis, obsession, compulsion, aggression, paranoia, and psychotism in relation to patients by cause of infertility, duration of infertility, age, education, and employment of the patients and their partners.

Results The mean age (SD) of the HI men and their partners were 33.37 (5.98) and 28.3(5.96) years compared to the SCI group which were 31.68 (3.43) and 28.4(4.87) years, respectively. This study showed that the level of anxiety, depression, paranoia, compulsion, and psychotism was higher than normal in our study groups. However,
\end{abstract}

M. Karimzadeh

Alzahra University, Tehran, Iran

N. Salsabili (ه)

IVF Department, Mirza Kouchak Khan Hospital, Tehran University of Medical Sciences. And Koassar Fertility and Impotency Center, Farmaniyeh, Lavasani Ave, Yeganeh Alley. No 7/200, Tehran, Iran

e-mail: nsalsabili56@yahoo.com

F. Akbariasbagh

Department of Ob/Gyn, School of Medicine Tehran University of Medical Sciences,

Tehran, Iran 
this was not significant within each group $(p>0.05)$. In SCI male, the level of depression, hypochondria, and compulsion increased by anxiety was significantly high $(p<0.05)$. The employment was associated with decreased phobia $(p<0.03)$. In SCI male's partners the duration of infertility and age significantly increased anxiety $(p<0.019)$, hypochondriosis and phobia $(p<0.033)$. The higher level of education was associated with greater decrease of psychotism $(p<0.03)$.In HI male group the compulsion and psychotism were interrelated significantly by higher level of anxiety $(p<0.00)$, and employment was related to lower levels of aggression (0.001). In HI male's partners, there was a direct relationship between the duration of the infertility with the level of anxiety, depression, hypochondriasis, and obsession $(p<0.05)$. The level of compulsion and aggression significantly decreased by education $(p<0.05)$.

Conclusion Adequate attention to infertile patients and their partners' psychological aspects and their treatment with cognitive, behavioral therapies and social supports before IVF/ICSI program is of great importance which may help to improve the quality of life in this population.

Keywords Psychological problems $\cdot$ Male infertility $\cdot$ IVF $\cdot$ Spinal cord injury · Infertility

\section{Introduction}

Each human is in search of continuation of its being by passing on its gene to the next generation. Therefore any incompetence in this beloved responsibility will cause emotional strains and in case of continuation of these strains it will lead to psychological impacts such as anxiety and depression [1-3].

Infertility with all its various reasons may present with different psychological symptoms and problems depending on each individual's beliefs and social expectations [4]. International Health Organization has defined infertility as a couple that has had intercourse for the duration of one year without usage of any infertility method and was unable to conceive. This will be significant when it extends to two years and the couple will recognize that there is a problem [5].

Infertility rate varies in different countries for instance $13 \%$ in Colombia, $8 \%$ in the United States of America, and $12 \%$ in Iran. In average $10 \%$ of the couples who are at the age of fertility are infertile [6].

Domar et al [7] showed that infertility is a very important reason for stress and anxiety in male and female, thus affecting the couple's sexual relationship and relationship as a whole. This incompetence will cause low self-esteem and interfere with couple's emotional, social, and financial resources [7]. Seibel et al. [2] and Koryntova et al [8] have shown that anxiety is extremely prevalent in infertile couples [2, 8]. Theireing et al. [3] reports a $25 \%$ increase of anxiety level in this group compared to the normal population. They also believe that $8-28 \%$ of these couples have a significant clinical anxiety. Ramzanzadeh et al [9] reported $40 \%$ depression and $87 \%$ anxiety in Iranian infertile female [9].

Kedem et al. [10] showed that self-respect and self-esteem is much lower in infertile male compared to normal population and they also suffer of a higher anxiety level. Physical pain and complaints are more prominent in this group, which 
is associated with lower productivity. Loss of hope, depression, and decrease in sexual desires are other manifestations in this population [10].

Tralatzis et al. [11] and Eugster et al. [12] independently show that anxiety and depression is higher in infertile male and female compared to the normal population. But depression is more common in female, and anxiety more common in male. Their studies also suggest that physical pain and complaints are more frequent in infertile male $[11,12]$.

Harlow et al. [1] demonstrated that infertility can cause stress in the couple and this stress can increase the levels of prolactin and cortisole which itself can be an attribute to infertility. Lunenfeld et al. [5] also support the idea that depression may directly interfere with the physiologic state of the body such as the level of prolactin, hypothalamic-pituitary adrenal axis, or the thyroid function, thus affecting the fertility and treatment methods [5]. Smeenk et al. [13] suggested that stress affects the successful outcome in IVF. Their studies also showed that there is a significant relationship between the adrenaline in the urine and the number of embryo-transfer (ET). The female patients who had a more successful outcome had less adrenaline in the follicles and more oocytes. Therefore the researchers concluded that there is an important relationship between adrenaline, fertility, and depression, which will affect the outcome of IVF [13]. Koryntova et al. [8] also showed that there is a significant relationship between anxiety and successful fertility by IVF. Women with higher anxiety level before IVF were less likely to become fertile [8]. Kee et al. [4] confirmed the same results and reported a significant increase in the levels of anxiety and depression in the female who were not successful in IVF treatment method [4].

Eugster et al. [12] reported a high anxiety level in infertile women before and after the treatment with IVF, but the women with episodic anxiety had much less chance of success in the repeat IVF treatments. Therefore there is a vicious cycle between infertility and emotional stress [12]. In general the researchers have suggested that by addressing these psychological issues and improving the patients emotional status would improve the chances for successful fertility. Therefore it is recommended to train the patients to cope with depression and anxiety symptoms and overcome these psychological squeals. Anderheim et al. [16] emphasize the importance of treating anxiety and depression before starting the treatment for infertility [16].

Duration of infertility is also another important factor in promoting anxiety and depression. Many researchers including Ramzanzadeh et al. [9] have shown that the duration of infertility increases the levels of depression and complication the treatments $[4,8,9,12,14]$.

One of the psychological disorders is post-traumatic stress disorder (PTSD) that can manifest after traumatic events such as earth quick, natural disaster and war that may cause serious physical injuries. Psychological problems including anxiety that follow these events have a serious impact on the patients' lives. Although a trauma or an event is essential in developing PTSD but the individuals emotional status, social, familial and cultural believes have an important impact $[6,14,15]$.

Since Iran and Iraq war many victims have suffered from serious physical injuries that have led to infertility. As a result of this disturbance some of these patients have been suffering from emotional stress such as anxiety, depression, and hypochondriasis [6].

Domar et al. [7] reported a high anxiety level in patients who have become infertile as a result of physical trauma to the point that this level parallels with cancer 
and cardiac patients [7]. Tralatzis et al. [11] suggest that depend on infertility of each partner, the level of psychological stress varies. Also other variables such as social, familial support and personal beliefs play an important role in developing these symptoms [11].

It is obvious that none of previous investigations focused on the other psychological problems such as, hypochondriasis, obsession, compulsion, aggression, paranoia and psychotism. Therefore, this study was aimed to investigate the psychological impact of infertility in HI male and their partners in comparison to SCI male infertile and their partners.

\section{Materials and Methods}

We surveyed psychological problems such as anxiety, depression, hypochondriasis, obsession, compulsion, aggression, paranoia, and psychotism in relation to patients by cause of infertility, duration of infertility, age, education, and employment of the patients and their partners.

A descriptive analytical study was performed on 115 subjects (couples) who attended for IVF/ICSI program recruited from IVF department of Mirza Kouchack khan Hospital, and Koassar Fertility and Impotency Center in Tehran, Iran. Consent was obtained from $31 \mathrm{HI}$ male with 20 of their partners and 34 SCI male with 30 of their partners and they completed the symptoms checklist (SCL-90) and cattle anxiety questionnaires. Both of these questionnaires have been translated and widely used in the Iranian community $[6,9]$. The Cattle questionnaire contains 40 components and addresses the symptoms of anxiety and has three levels of 0,1 , and 2[9]. Each questionnaire result is averaged and curved from 0 to 10.

$0-3$ : Calm individuals and stress free

4-6: Mild anxiety

7-8: Moderate anxiety

9-10: Need psychological treatment for anxietySCL-90 is also translated and evaluated in the Iranian psychological society, which contains 90 issues such as anxiety, aggression, paranoia, phobia, and compulsion [6]. The results are scored 0, 2, and 4, which each individual's score is calculated and curved. An average of 1 and higher represent psychological disorders and 3 and higher represents pshycotism and depression.

All SCI patients were injured during the Iraq-Iran war and were being supported by the National Janbazan Organization. The HI males were announced infertile based on either clinical or laboratorial studies. The partners of the SCI male and HI male were studied extensively by the means of clinical, hormonal, radiological, and laparoscopic and were announced to be in healthy condition and had no reason to be infertile.

\section{Statistics}

The Pearson's correlation coefficient was obtained for variables. The stepwise regression analysis was performed to select the important predictors of dependent 
variables. Multiple analysis of variance (MANOVA) was used to compare groups formed by categorical independent variables.

The SPSS V, 11.5 was used for analysis. The alpha level was set at 0.05 .

\section{Results}

Table 1 shows demographic characteristic of the groups.

$97 \%$ of $\mathrm{HI}$ male and $20 \%$ of their partners were employed compared to SCI male and their partners which were $38 \%$ and $10 \%$ respectively.

Table 2 presents mean (SD) of the symptoms. In both HI and SCI groups, the mean of all psychological symptoms (SCL-90) was greater than 1 except for phobia. The Cattle anxiety questionnaire showed the mild anxiety in all four groups (average; 4-6).

After MANOVA studies among SCI and HI male and their partners, no significant difference among groups were identify in spite of high level of depression and anxiety $(p>0.05)$.

\section{Spinal Cord Injured Male}

The duration of infertility had a significant relationship with the cattle anxiety questionnaire $(p<0.03, r=0.31)$. But none of the variables; age, education, duration of infertility was not able to identify the level of cattle anxiety. Education had an inverse relationship with hypochondriasis $(p<0.04, r=-0.29)$. Employment had a significant negative relationship with hypochondriasis $(p<0.04, r=0.391)$, compulsion $(p<0.04, r=0.36)$, and paranoia $(p<0.01, r=-0.363)$.

Among the variables studies in SCL-90, employment was the only factor that could predict paranoia. This variable predicted $13 \%$ of the paranoia (Table 3 ).

Step by step regression analysis showed that compulsion predicted $70 \%$ of the first step, hypochondrias $10 \%$ of the second step, and depression $2 \%$ of the third step (Table 4).

\section{Partners of SCI Male}

Age had a significant relationship with the duration of infertility $(p<0.016$, $r=0.388$ ), but none of the variables age, education, duration of infertility was not

Table 1 Demographic characteristics of groups

\begin{tabular}{|c|c|c|c|c|c|}
\hline \multirow[t]{2}{*}{ Group } & \multirow[t]{2}{*}{ Number } & \multirow{2}{*}{$\begin{array}{l}\text { Mean of } \\
\text { Age (SD) }\end{array}$} & \multicolumn{2}{|l|}{ Education } & \multirow{2}{*}{$\begin{array}{l}\text { Duration of Infertilility } \\
\text { per year (SD) }\end{array}$} \\
\hline & & & $\begin{array}{l}\text { Lower } \\
\text { diploma }\end{array}$ & $\begin{array}{l}\text { Higher } \\
\text { diploma }\end{array}$ & \\
\hline SCI male & 34 & $31.68(3.43)$ & $n=2265 \%$ & $n=1235 \%$ & $5.5(2.76)$ \\
\hline SCI partner's & 30 & $28.42(4.87)$ & $n=2687 \%$ & $n=413 \%$ & $5.5(2.76)$ \\
\hline HI male & 31 & $33.37(5.98)$ & $n=2684 \%$ & $n=516 \%$ & $5.9(4.19)$ \\
\hline HI partner's & 20 & $28.3(5.96)$ & $n=1890 \%$ & $n=210 \%$ & $5.9(4.19)$ \\
\hline
\end{tabular}


Table 2 Descriptive indexes of psychological variables in infertile groups

\begin{tabular}{|c|c|c|c|c|c|c|c|c|c|c|c|c|}
\hline \multirow[t]{3}{*}{ Variable } & \multicolumn{12}{|c|}{ Group } \\
\hline & \multicolumn{3}{|c|}{ SCI male } & \multicolumn{3}{|c|}{ SCI partner's } & \multicolumn{3}{|c|}{ HI male } & \multicolumn{3}{|c|}{ HI partner's } \\
\hline & no & Mean & $\mathrm{SD}$ & no & Mean & $\mathrm{SD}$ & no & Mean & $\mathrm{SD}$ & no & Mean & $\mathrm{SD}$ \\
\hline Anxiety- SCL-90 & 34 & 1.089 & 0.87 & 31 & 1.29 & 0.77 & 30 & 1.15 & 0.84 & 20 & 5.73 & 1.767 \\
\hline Depression & 34 & 1.034 & 0.89 & 31 & 1.34 & 1.02 & 30 & 1.06 & 0.88 & 20 & 1.28 & 1.007 \\
\hline Hypochondriasis & 34 & 1.2 & 0.87 & 31 & 1.18 & 0.83 & 30 & 1.19 & 1.04 & 20 & 1.19 & 0.67 \\
\hline Obsession & 34 & 1.05 & 0.95 & 31 & 1.32 & 0.94 & 30 & 1.24 & 0.79 & 20 & 1.45 & 0.83 \\
\hline Compulsion & 34 & 1.166 & 0.92 & 31 & 1.22 & 0.8 & 30 & 1.2 & 0.89 & 20 & 1.33 & 0.86 \\
\hline Aggression & 34 & 1.157 & 1.06 & 31 & 1.03 & 0.75 & 30 & 1.04 & 0.8 & 20 & 1.16 & 0.95 \\
\hline Paranoia & 34 & 1.339 & 0.82 & 31 & 1.4 & 0.9 & 30 & 1.74 & 0.96 & 20 & 1.7 & 0.92 \\
\hline Phobia & 34 & 0.81 & 1.02 & 31 & 1.75 & 4.99 & 30 & 0.66 & 0.7 & 20 & 0.81 & 0.809 \\
\hline Psychotism & 34 & 0.93 & 0.95 & 31 & 1.58 & 3.14 & 30 & 1.21 & 0.89 & 20 & 1.06 & 0.87 \\
\hline Anxiety-cattle & 34 & 5.76 & 1.689 & 31 & 5.58 & 1.92 & 30 & 6.5 & 1.71 & 20 & 6.7 & 1.41 \\
\hline
\end{tabular}

Table 3 Results of stepwise regression of psychological variables (SCL-90) in infertile groups

\begin{tabular}{|c|c|c|c|c|c|c|c|}
\hline \multirow[t]{2}{*}{ Variables } & \multicolumn{7}{|l|}{ Group } \\
\hline & Criterion variable & $\begin{array}{l}\text { Regression } \\
\text { variables }\end{array}$ & $R$ & $R^{2}$ & $\begin{array}{l}\text { Standard } \\
\text { error }\end{array}$ & $p_{\text {value }}$ & $F$ \\
\hline SCI male & Paranoia & occupation & 0.363 & 0.132 & 0.777 & 0.03 & 4.85 \\
\hline \multirow[t]{4}{*}{ SCI partner's } & Anxiety & Age & 0.419 & 0.175 & 0.718 & 0.01 & 4.3 \\
\hline & Hypochondriasis & Age & 0.408 & 0.167 & 0.776 & 0.02 & 5.8 \\
\hline & Phobia & Education & 0.1418 & 0.174 & 4.61 & 0.01 & 6.134 \\
\hline & Psychotism & Education & 0.377 & 0.142 & 2.95 & 0.03 & 4.808 \\
\hline HI male & Aggression & Occupation & -0.459 & 0.21 & 0.726 & 0.01 & 7.49 \\
\hline \multirow[t]{6}{*}{ HI partner's } & Anxiety & Duration of infertility & 0.57 & 0.325 & 15.075 & 0.009 & 6.43 \\
\hline & Depression & Duration of infertility & -0.544 & 0.296 & 0.8683 & 0.01 & 7.12 \\
\hline & Psychotism & Duration of infertility & -0.501 & 0.251 & 0.602 & 0.02 & 6.042 \\
\hline & Obsession & Duration of infertility & -0.512 & 0.262 & 0.793 & 0.02 & 6.385 \\
\hline & Compulsion & Education & 0.543 & 0.293 & 0.749 & 0.01 & 7.522 \\
\hline & Paranoia & Education & 0.501 & 0.251 & 0.821 & 0.02 & 6.022 \\
\hline
\end{tabular}

Table 4 Results of stepwise regression of anxiety by psychological variables (SCL-90) in infertile groups

\begin{tabular}{|c|c|c|c|c|c|c|c|c|}
\hline Group & $\begin{array}{l}\text { Criterion } \\
\text { variable }\end{array}$ & Steps & $\begin{array}{l}\text { Regression } \\
\text { variables }\end{array}$ & $R$ & $R^{2}$ & $\begin{array}{l}\text { Standard } \\
\text { error }\end{array}$ & $p_{\text {value }}$ & $F$ \\
\hline \multirow[t]{3}{*}{ SCI Male } & \multirow[t]{3}{*}{ Anxiety } & $1 \mathrm{st}$ & Compulsion & 0.869 & 0.756 & 0.439 & 0.000 & 98.88 \\
\hline & & 2nd & Hypochondriasis & 0.927 & 0.86 & 0.338 & 0.000 & 22.95 \\
\hline & & $3 r d$ & Depression & 0.929 & 0.88 & 0.314 & 0.023 & 5.74 \\
\hline \multirow[t]{2}{*}{ SCI Partner's } & \multirow[t]{2}{*}{ Anxiety } & $1 \mathrm{st}$ & Hypochondriasis & 0.791 & 0.626 & 0.48 & 0.000 & 48.53 \\
\hline & & 2nd & Paranoia & 0.861 & 0.742 & 0.409 & 0.001 & 13.57 \\
\hline \multirow[t]{2}{*}{ HI Male } & \multirow[t]{2}{*}{ Anxiety } & $1 \mathrm{st}$ & Compulsion & 0.862 & 0.742 & 0.437 & 0.000 & 80.7 \\
\hline & & 2nd & Psychotism & 0.895 & 0.8 & 0.392 & 0.000 & 7.8 \\
\hline
\end{tabular}

able to identify the level of cattle anxiety. There was a significant relationship between age and duration of infertility $(p<0.016, r=0.388)$ in SCL-90. The step-bystep regression analysis showed that among all the variables studied, age was the only variable that was able to predict $17 \%$ of anxiety in SCL-90 (Table 3). In this group age showed a significant positive (16\%) relationship with compulsion 
$(p<0.01, r=0.319)$. Education showed a significant negative relationship with paranoia $(p<0.03, r=0.36)$.

Regression analysis showed that education could predict $17 \%$ of phobia variant and $14 \%$ of compulsion variant in this group (Table 3). In step-by-step regression analysis of anxiety with SCL-90 variables it was shown that anxiety was related to depression $(p<0.00, r=0.7)$, hypochondriasis $(p<0.00, r=0.79)$, obsession $(p<0.00, r=0.73)$, compulsion $(p<0.00, r=0.00)$, aggression $(p<0.00, r=0.6)$, and paranoia $(p<0.00, r=0.6)$. The result of these analysis showed that among the variables mentioned, hypochondriasis and paranoia are the only ones that can determine parts of thee anxiety (Table 4).

\section{Healthy Infertile Male}

Employment had a strong negative relationship with aggression (Table 3); this variable was able to predict $21 \%$ of aggression variable. There was a significant relationship among anxiety and variables; depression $(r=0.84)$, hypochondria$\operatorname{sis}(r=0.8)$, obsession $(r=0.85)$, compulsion $(r=0.860$, aggression $(r=0.57)$, paranoia $(r=0.74)$, phobia $(r=0.71)$, and psychosis $(r=0.83)$. Among the variables mentioned compulsion (74\%) and psychosis (5\%) were able to determine level of anxiety (Table 4).

\section{Partners of Healthy Infertile Male}

There was an association between the duration of infertility and anxiety SCL-90 and the step-by-step regression analysis showed that $32 \%$ of anxiety variable is identifiable (Table 3). Education was significantly associated with depression $(p<0.03$, $r=0.408)$ and depression itself was associated with the duration of infertility $(p<0.0007, r=-0.544)$. Based on the regression analysis, duration of infertility can identify $29 \%$ of the variable of depression (Table 3).

Education had a significant association with hypochondriasis $(p<0.017$, $r=0.474$ ), but the duration of infertility had a negative relationship with hypochondriasis. Step by step regression analysis could only identify $25 \%$ of the hypochondriasis variable and $26 \%$ of obsession. There was a negative association between duration of infertility and obsession (Table 3).

There was a positive and significant relationship between education and compulsion and aggression $(p<0.03, r=0.41)$ and was able to identify the paranoia variable (Table 3).

\section{Discussion}

The results of this study showed that all four groups, SCI male and their partners, HI male and their partners suffer from anxiety, depression, compulsion, obsession, paranoia, and hypochondriasis that is more common than normal population (Tables 3 and 4) which is consistent with Ramezanzadeh [9] and Koryntova [8] reports. This study also showed that education and employment had an important role in decrease of hypochondriasis, compulsion and paranoia in SCI male group. In 
addition it was observed that with increase of anxiety in this group hypochondriasis and compulsion increases as well. Education was also an important factor in the partners of the SCI male and was associated with decrease psychosis and phobia. These women would suffer more from anxiety and hypochondriasis with increase in age.

The more educated HI males sleeked medical attention sooner and the ones with employment had a lower rate of aggression. In this group the individuals with anxiety were associated more with compulsion and psychosis (Table 4).

The most problems were observed in the partners of HI males. In this group with increase in the length of infertility, anxiety would increase as well. The women who had recently realized the infertility of their partners were more depressed and suffered more from hypochondriasis and obsession (Table 3). This study also suggests that the women that have higher education levels showed less aggression and compulsion, which has been consistent with previous reports [12-14].

Anxiety and depression were related and were prominent in partners of $\mathrm{HI}$ male, which was also consistent with other reports [2, 4, 8, 9, 13]. It appears that the HI couples have more social problems compared to SCI couples. Also it appears that the knowledge of infertility in SCI male is associated with decrease emotional stress and depression [6]. In this study compulsion and paranoia are very prominent in all four groups and they are mainly the most important factors in anxiety level in the HI male and their partners. Infertility in addition to the length on infertility was an important factor in causing anxiety in the partners of $\mathrm{HI}$ males, which was again consistent with previous reports [13-16]. Having the knowledge of infertility in the SCI male and their partners and the social support are some of the important factor that make these groups vary in their presentations. In addition the fact that all their medical expenses are paid by the Janbazan organization makes psychological stress less in this group. Furthermore the social status and the respect that the SCI patients and their families receive affect their emotional and stress level.

In conclusion the infertile couple suffers from various manifestations of psychological symptoms. Unfortunately regardless of the improvement in technical and medical capabilities such as Assisted Reproductive Technology (ART) programs and IVF/ ICSI the rate of success is low and it is suggested that psychological disturbances are one of the reasons of ART failure. Therefore we recommend variety of methods in addressing and treating these psychological manifestations before ART, or IVF/ ICSI program.

Acknowledgment We wish to thank Rose Khavari M.D, Resident at Baylor University, Houston, Texas, for her kind assistance to provide this manuscript.

\section{References}

1. Harlow, C.R., Fahy, U.M., Talbot, W.M., Wardle, P.G., Hull, M.G.: Stress and Stress-related hormones during in-vitro fertilization treatment. Hum. Reprod. 11(2), 274-279 (1996)

2. Seibel, M.M., Taymor, M.L.: Emotional aspects of infertility. Fertil. Steril. 37, 137-145 (1982)

3. Theireing, P., Beaurepaire, J., Jones, M., Saunders, D., Tennant, C.: Mood state as a predictor of treatment outcome after in vitro fertilization/embryo transfer technology (IVF/ET). J. Psychosom. Res. 37(5), 481-91 (1993)

4. Kee, B.S., Jung, B.J., Lee, S.H.: A study on psychological strain in IVF patients. J. Assist. Reprod. Genet. 17(8), 445-448 (2000) 
5. Lunenfeld, B., Insler, V., Glezerman, M.: Diagnosis and Treatment of functional infertility, 3rd., rev. ed., pp. 16-33. Blackwell wissenschafts, Berlin (1992)

6. Salsabili, N., Karimzadeh, M., Ahmadvand, M.A., Asadi, M.H., Brati, F.: A comparative study of Psychological Problem and anxiety levels in between spinal cord injured infertile couples with normal infertile couples. Iran. Med. J. Hakim 3(3), 207-214 (2000)

7. Domar, A.D., Zuttermeister, P.C., Friedman, R.: The Psychological impact of infertility: a comparison parents other medical conditions. J. Psychosom. Obstet. Gynecol. 14, 45-52 (1993)

8. Koryntova, D., Sibtova, K., Klouckova, E., Cepicky, P., Rezabek, K., Zivny, J.: Effect of Psychological factors of success of invitro fertilization. Ceska Gynekol 66(4), 264-269 (2001)

9. Ramzanzadeh, F., Aghssa, MS., Abedinia, N., Zayeri, F., Khanafshar, N., Shariat, M., Jafarabadi, M.: A survey of relationship between anxiety, depression and duration of infertility. BMC Women's Health 4, 1-9 (2004). doi: 10. 1186/1472-6874-4-9 .

10. Kedem, P., Mikulincer, M., Nathanson, Y.E.: Psychological aspect of male infertility. Br. J. Medical Psychol. 63(Pt.1), 73-80 (1990)

11. Tralatzis, I., Tarlatzis, B.C., Diakogiannis, I., Bontis, J., Lagos, S., Gavriilidou, D., Mantalenakis, S.: Psychological impact of infertility on Greek Couples. Hum Reprod 8(3), 369-401 (1993)

12. Eugster, A., Vingerhoets, A.J., Van Heck, G.l., Merkus, J.M.: The effect of episodic anxiety on an in vitro fertilization and intracytoplasmic sperm injection Treatment outcome. A pilot study, Department of psychology and Health. Tilburg university, Tilburg the Netherlands 25(1), 57-65 (2004)

13. Smeenk, J.M.J., Verhaak, C.M., Eugster, A., van Minnen, A., Zielhuis, G.A., Braat, D.D.: The effect of anxiety and depression on the outcome of in vitro fertilization. Hum Reprod 16(7), 1420-1423 (2001)

14. Smeenk, J.M.J., Verhaak, C.M., Vingerhoets, A.J.J.M., Sweep, C.G.J., Merkus, J.M.W.M., Willemsen, S.J., Minnen, A.V., Straatman, H., Braat, D.D.M.: Stress and outcome success in IVF : The role of self reports and endocrine variables. Hum Reprod Apr 20(4), 991-996 (2005)

15. Stoleru, S., Cornet, D., Vaugeois, P., Fermanian, J., Magnin, F., Zerah, S., Spira, A.: The influence of psychological factors on the outcome of fertilization step of in vitro fertilization. J. Psychosom. Obstet. Gynaecol. 18(3), 189-202 (1997)

16. Anderheim, L., Holter, H., Bergh, C., Moller, A.: Does psychological stress affect the outcome of in vitro fertilization? Hum Reprod 20(10), 2969-2975 (2005) - E. pub 2005 Aug 25. 